\title{
Feasibility of salvage endoscopic resection for patients with locoregional failure after definitive radiotherapy for pharyngeal cancer
}

Authors

Institutions
Hironaga Satake' ${ }^{1}$, Tomonori Yano ${ }^{1}$, Yusuke Yoda ${ }^{1}$, Satoshi Fujii' ${ }^{2}$, Sadatomo Zenda ${ }^{3}$, Toshifumi Tomioka ${ }^{4}$, Takeshi Shinozaki $^{4}$, Masakazu Miyazaki ${ }^{4}$, Kazuhiro Kaneko' ${ }^{1}$, Ryuichi Hayashi $^{4}$

Institutions are listed at the end of article. submitted

1. December 2014 accepted after revision 17. March 2015

\section{Bibliography}

DOI http://dx.doi.org/

10.1055/s-0034-1392093

Published online: 26.5.2015

Endosc Int Open 2015; 03:

E274-E280

(c) Georg Thieme Verlag KG

Stuttgart · New York

E-ISSN 2196-9736

\section{Corresponding author}

Tomonori Yano, MD

Department of

Gastroenterology

Endoscopy Division

National Cancer Center Hospital

East

6-5-1, Kashiwanoha

Kashiwa 277-8577

Japan

Fax: +81-4-7131-4724

toyano@east.ncc.go.jp
License terms

(ब)(1) $\ominus \circledast$
Background and study aims: Local failure after radiation therapy for pharyngeal squamous cell carcinoma (PSCC) is problematic. The safety of endoscopic resection for lesions within the radiation therapy (RT) field has not been assessed. We evaluated salvage endoscopic resection in patients with locoregional failure after definitive radiotherapy for PSCC.

Patients and methods: We retrospectively evaluated the clinical outcomes and long-term survival of 16 patients initially treated with more than $60 \mathrm{~Gy}$ of radiation for PSCC. These patients later presented with 19 superficial metachronous or recurrent PSCC lesions within the radiation field and were treated with salvage endoscopic resection.

Results: Local recurrence developed at the primary site in 3 patients after a complete response

\section{Introduction}

$\nabla$

Radiation therapy (RT) is a potentially curative treatment for patients with pharyngolaryngeal squamous cell carcinoma (PSCC). External beam RT with or without concurrent chemotherapy is used for head and neck cancer with the goal of preserving function [1-3]. Unfortunately, local failure after definitive RT for PSCC remains a major problem. In addition, patients with PSCC are at risk for the development of multiple squamous cell carcinomas (SCCs) [4,5] and sometimes develop a second primary SCC within the RT field. Radiation leads to changes in the mucosa, such as chronic inflammation with hypervascularity and swelling, so that it is difficult to detect second primary lesions or superficial recurrent lesions with conventional white-light endoscopic screening. Narrow-band imaging (NBI) endoscopy can detect early superficial PSCCs, which appear as well-demarcated brownish areas that on closer view exhibit scattered brown dots [6-8]. There is evidence that NBI endoscopy has a high detection to RT. The other 13 had multiple metachronous squamous cell carcinomas within the original RT field. Major complications associated with salvage endoscopic resection included aspiration pneumonia in 1 patient and a requirement for temporary tracheostomy in 3 patients. During a median follow-up period of 37 months (range, 2-72 months), 13 patients had no recurrence, 2 patients developed local recurrence, and 1 patient developed lymph node metastases. At present, 5 of the 16 patients have died: 2 of PSCC progression, 1 of esophageal squamous cell carcinoma, and the remaining 2 of unknown causes. The 3year survival rate was $68.6 \%$.

Conclusions: Endoscopic resection is a potentially curative salvage treatment option for patients with superficial locoregional failure after definitive radiotherapy for PSCC.

rate for recurrent lesions following RT [9]. In esophageal carcinoma, salvage endoscopic resection is a treatment strategy for superficial failure lesions within the RT field [10]. Although the safety and clinical benefit of endoscopic resection as an initial treatment for superficial PSCC have been reported [11-15], little is known of the safety of endoscopic resection for recurrent or metachronous lesions within an RT field [16].

Here, we conducted a retrospective study to evaluate the safety and efficacy of salvage endoscopic resection for locoregional failure after definitive RT for PSCC.

\section{Patients and methods \\ $\nabla$}

From June 2002 to July 2011, 163 consecutive patients with superficial primary or recurrent PSCC were treated with endoscopic resection at the $\mathrm{Na}$ tional Cancer Center Hospital East, Kashiwa, Japan. Patients undergoing endoscopic resection for recurrent or metachronous lesions within a 

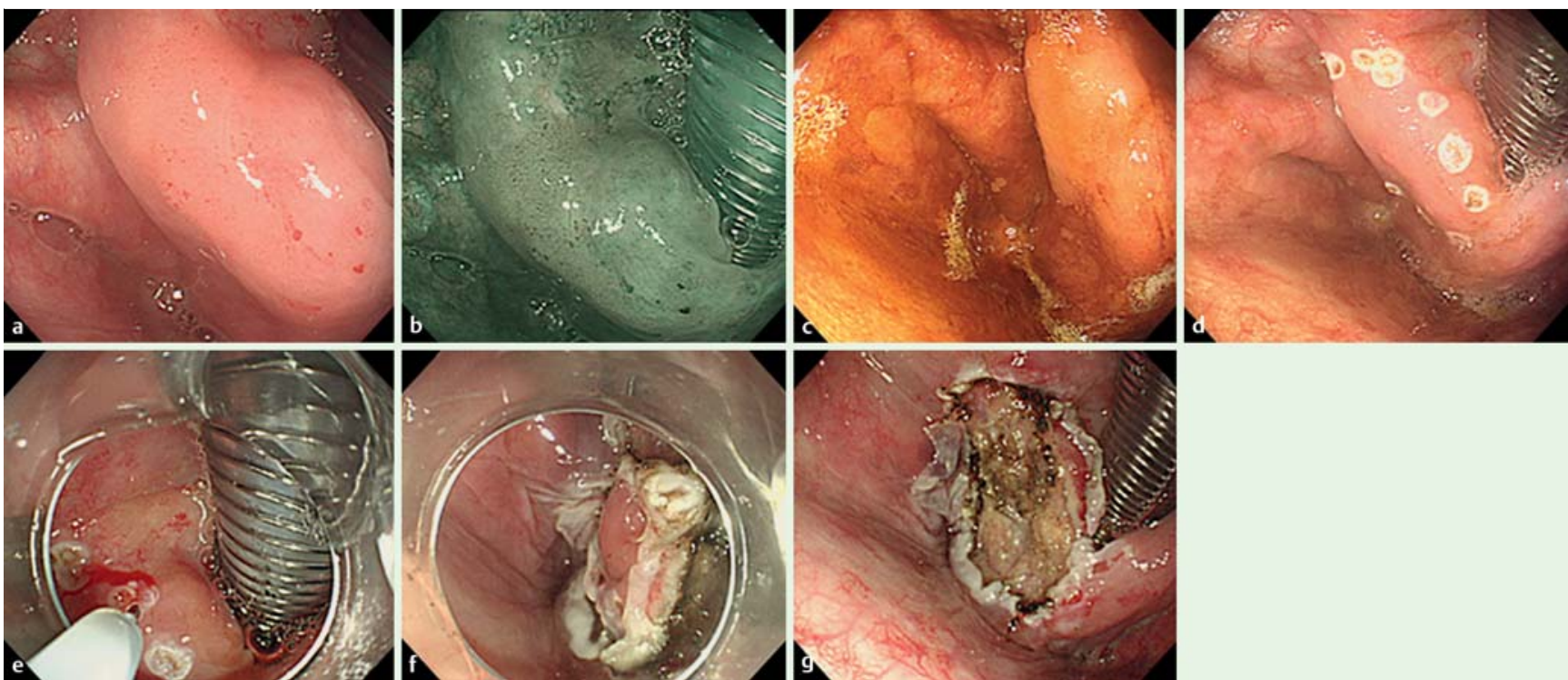

Fig. 1 Salvage endoscopic submucosal dissection with a DualKnife in a patient with locoregional failure after definitive radiotherapy for pharyngeal cancer a Endoscopy with white light shows a reddish, flat lesion of the left aryepiglottic fold against the background of the white color of the edematous piriform sinus. b Endoscopy with narrow-band imaging shows a brownish neoplastic area. c Chromoendoscopy with $2.0 \%$ iodine staining to demarcate the lesion. d Marking around the lesion with a DualKnife. e An adequate volume of $0.9 \%$ saline solution mixed with a low volume of epinephrine $(0.02 \mathrm{mg} / \mathrm{mL})$ is injected into the subepithelial layer beneath the lesion. $\mathbf{f}$ Circumferential incision made with a DualKnife. $\mathbf{g}$ Induced ulcer after removal of the lesion.

prior RT field were defined as the post-RT salvage group, and patients who underwent endoscopic resection for superficial PSCC with no prior RT as the non-RT group." Before endoscopic resection, all lesions had been pathologically diagnosed as SCC according to World Health Organization (WHO) criteria with the examination of biopsy specimens [17]. Indications for endoscopic resection for superficial PSCC were the following: (i) histologic confirmation of a PSCC lesion in NBI-targeted biopsy specimens; (ii) absence of highly protruding areas or ulceration beyond suspected minor invasion to the subepithelial layer; (iii) absence of bilateral involvement of the pharyngeal spaces or spread into the deep laryngeal space (e.g., lesions $>4 \mathrm{~cm}$ ); (iv) absence of lymph node or distant metastases on physical examination, contrast-enhanced computed tomography, or positron emission tomography/computed tomography; and (v) provision of the patient's written informed consent. The inclusion criterion for the study was histologically proven recurrent PSCC after definitive RT with no lymph node or distant metastases. Results of the post-RT salvage group were compared with those of the non-RT group. The study protocol was approved by the institutional review committee (study number 2011-026).

\section{Endoscopic resection procedures}

Endoscopic resection involved endoscopic mucosal resection with use of a cap (EMR-C), endoscopic submucosal dissection (ESD) (with dissection from the subepithelial layer), or endoscopic laryngopharyngeal surgery (ELPS). All procedures were performed with the patient in the supine position and under general anesthesia. A curved-type rigid laryngoscope (Nagashima Medical Instruments, Tokyo, Japan) was inserted by a head and neck surgeon to widen the pharyngeal space. Lesion extent was confirmed by NBI endoscopy and $2.0 \%$ iodine staining, and lesions were clearly recognized as unstained areas on iodine chromoendoscopy.

We used a single-channel upper gastrointestinal endoscope with a water jet system (GIF-H260Z, GIF-Q260J; Olympus, Tokyo, Ja- pan) and a high-frequency generator with an automatically controlled system (ICC 200; ERBE Elektromedizin GmbH, Tübingen, Germany) set at Endocut mode, $120 \mathrm{~W}$, effect 2 for circumferential incision/forced coagulation or at $50 \mathrm{~W}$ for dissection.

The details of the salvage EMR-C method are as follows [18]: A cap with a diameter of $18.1 \mathrm{~mm}$ (D-206-06; Olympus) was fitted to the tip of the endoscope. Saline solution at a concentration of $0.9 \%$ was injected into the subepithelial layer to create a subepithelial cushion. A fine semilunar snare wire (SD-7P; Olympus) was passed through the biopsy channel of the endoscope and prelooped around the gutter at the tip of the cap.With endoscopic suction, the lesion was drawn into the cap, strangulated by closure of the snare wire, and resected with high frequency electrocautery. The resected specimen was drawn into the cap and withdrawn together with the endoscope.

The details of the ESD method (with dissection from the subepithelial layer) with a knife (DualKnife, Olympus) are as follows ( $\bullet$ Fig. 1): Marking spots were made around the circumference of the lesion with the knife to determine the dissection range. Saline solution at a concentration of $0.9 \%$ was injected into the subepithelial layer to create a subepithelial cushion. The initial incision was made just outside the marking spot, and a circumferential incision around the lesion was made with the knife. Subsequently, additional saline solution was injected into the subepithelial layer, allowing dissection of the subepithelial layer with the same device. After the lesion had been resected, vessels were coagulated to prevent delayed bleeding.

The details of the endoscopic laryngopharyngeal surgery (ELPS) method are as follows ( $\bullet$ Video 1): After evaluation of the lesion

\section{Video 1}

Salvage endoscopic laryngopharyngeal surgery procedure.

online content including video sequences viewable at: www.thieme-connect.de 
Table 1 Patient characteristics $(n=163)$.

\begin{tabular}{|c|c|c|c|}
\hline & $\begin{array}{l}\text { Post-RT sal- } \\
\text { vage }(n=16)\end{array}$ & $\begin{array}{l}\text { Non-RT } \\
(n=147)\end{array}$ & $P$ value \\
\hline Median age (range), y & $66(52-80)$ & $64(42-88)$ & 0.180 \\
\hline Male / female, n (\%) & $16 / 0(100 / 0)$ & $143 / 4(97 / 3)$ & 0.505 \\
\hline \multicolumn{4}{|c|}{ Multiple Lugol-voiding lesions, $n(\%)$} \\
\hline Positive & $11(69)$ & $124(84)$ & \\
\hline Negative & $4(25)$ & $19(13)$ & 0.385 \\
\hline Unknown & $1(6)$ & $4(3)$ & \\
\hline \multicolumn{4}{|c|}{ Primary site of prior lesion, $\mathrm{n}(\%)$} \\
\hline Oropharynx & $5(31)$ & & \\
\hline Hypopharynx & $3(19)$ & & \\
\hline Larynx & $8(50)$ & & \\
\hline $\begin{array}{l}\text { Median total dose of RT } \\
\text { (range), Gy }\end{array}$ & $66(60-76.8)$ & & \\
\hline CR to definitive RT, $n(\%)$ & (100) & & \\
\hline
\end{tabular}

$\mathrm{RT}$, radiotherapy; CR, complete response.

extent with NBI magnified endoscopy and iodine chromoendoscopy, marking spots were made around the circumference of the lesion with the knife to determine the dissection range. The initial incision was the same as for ESD. After a circumferential incision had been made, a curved-type retention forceps (Nagashima) and an electrosurgical knife (KD-Y0007; Olympus) were inserted orally. The retention forceps allowed us to apply countertension, after which the lesion was resected with the electrosurgical knife under endoscopic observation.

Finally, we confirmed the residual lesion with $2.0 \%$ iodine staining, and then the head and neck surgeon evaluated the degree of laryngeal edema. If intense bilateral laryngeal edema was present, a temporary tracheostomy was performed to prevent airway obstruction.

The choice of modality was left to the therapeutic endoscopist performing the procedure. Before 2006, all endoscopic resection procedures were performed with the EMR-C method. After that, the ESD method was adopted, and ELPS was used for large lesions to achieve en bloc resection.

If the patient experienced a severe symptom, such as sore throat, high fever, or dyspnea, checkup endoscopy was carried out 1 day after the endoscopic resection to assess the degree of laryngeal edema and exclude visible bleeding vessels. If the edema was mild and the absence of bleeding confirmed, the patient was allowed to drink water 2 days after endoscopic resection and to ingest semisolid food thereafter.

\section{Pathologic evaluation and follow-up after endoscopic resection}

All resected specimens were fixed in $10 \%$ formalin, cut into longitudinal slices measuring $2 \mathrm{~mm}$ in width, and embedded in paraffin wax. The tissue specimens were cut at a thickness of $2 \mu \mathrm{m}$ and stained with hematoxylin and eosin. All sections underwent routine pathologic evaluation according to WHO criteria, including an assessment for lymphatic/venous invasion, by experienced pathologists [17]. Pathologic T stage was based on the surface dimensions of the tumor, which is the most important parameter for primary tumor staging in pharyngeal cancer. $\mathrm{T} 1$ is $2 \mathrm{~cm}$ or less in greatest dimension, $\mathrm{T} 2$ is more than $2 \mathrm{~cm}$ but not more than $4 \mathrm{~cm}$ in greatest dimension, and T3 is more than $4 \mathrm{~cm}$ in greatest dimension. Although there are no accepted definitions of superficial PSCC, the guidelines for head and neck cancer proposed by the Japan Society for Head and Neck Cancer define superficial PSCC as "a tumor limited to the subepithelial layer re-

\begin{tabular}{|c|c|c|c|}
\hline & $\begin{array}{l}\text { Post-RT salvage } \\
(n=22)\end{array}$ & $\begin{array}{l}\text { Non-RT } \\
(\mathrm{n}=181)\end{array}$ & $P$ value \\
\hline $\begin{array}{l}\text { Median lesion size } \\
\text { (range), mm }\end{array}$ & $15(4-50)$ & $15(2-50)$ & 0.980 \\
\hline Macroscopic type, n (\%) & & & 0.044 \\
\hline $0-1$ & $2(9)$ & $5(3)$ & \\
\hline 0 -IIa & $9(41)$ & $49(27)$ & \\
\hline $0-I I b$ & $9(41)$ & $96(53)$ & \\
\hline 0 -IIc & $2(9)$ & $31(17)$ & \\
\hline Location, n (\%) & & & 0.013 \\
\hline Hypopharynx & $16(73)$ & $155(86)$ & \\
\hline Piriform sinus & $10(45)$ & $128(71)$ & \\
\hline Posterior wall & $3(14)$ & $16(9)$ & \\
\hline Post-cricoid area & $3(14)$ & $11(6)$ & \\
\hline Orophaynx & $6(27)$ & $26(14)$ & \\
\hline Posterior wall & $2(9)$ & $15(8)$ & \\
\hline Lateral wall & $0(0)$ & $3(2)$ & \\
\hline Vallecula & $2(9)$ & $6(3)$ & \\
\hline Uvula & $1(5)$ & $0(0)$ & \\
\hline Tonsil & $1(5)$ & $2(1)$ & \\
\hline
\end{tabular}

RT, radiotherapy; 0-I, protruded type; 0-Ila, slightly elevated type; 0-Ilb, flat type; 0 -Ilc, slightly depressed type.

gardless of lymph node and distant metastasis" [19]. Moreover, subepithelial invasion is difficult to diagnose because there is no lamina muscularis mucosae in the pharynx [20]. We defined subepithelial invasion by the observation of at least one solitary carcinoma cell nest in the subepithelial region [21].

All patients were enrolled in a strict follow-up program in collaboration with the referring head and neck surgeon. Follow-up examinations were performed every 3 months within the first year after treatment, and then at 6-month intervals. Each checkup examination included NBI endoscopy, physical examination, and computed tomography.

If any of the follow-up examinations revealed residual neoplastic tissue or secondary malignant lesions (metachronous or recurrent lesions), local endoscopic resection or partial resection was repeated after the patient had been provided with appropriate information. Lesions occurring near the primary site - for example, at the margin of a scar after endoscopic resection - were defined as local recurrences.

\section{Statistics}

Statistical analysis of the long-term outcomes was done with the Kaplan-Meier method. Continuous data were compared with the Mann-Whitney U test. The Pearson chi-squared test or Fisher's exact test was used to analyze categorical data and compare proportions.

All statistical analyses were done with SPSS 22.0 (IBM, Armonk, New York, USA). All statistical tests were two-tailed, and statistical significance was defined as a $P$ value of less than 0.05 .

\section{Results \\ $\boldsymbol{\nabla}$}

\section{Patients and lesions}

- Table 1 lists the characteristics of the post-RT salvage and nonRT endoscopic resection groups. Salvage endoscopic resection was used to treat 16 patients with 22 superficial PSCCs occurring within the RT field. All patients in the salvage group had been treated with a radiation dose of more than $60 \mathrm{~Gy}$ (median dose, 


\begin{tabular}{|c|c|c|c|}
\hline & Post-RT salvage $(n=22)$ & Non-RT $(n=181)$ & $P$ value \\
\hline Endoscopic resection method, $\mathrm{n}(\%)$ & & & 0.463 \\
\hline EMR-C & $16(73)$ & $119(66)$ & \\
\hline ESD & $6(27)$ & $56(31)$ & \\
\hline ELPS & $0(0)$ & $6(3)$ & \\
\hline Mean procedure time (SD), min & $70(40)$ & $61(41)$ & 0.809 \\
\hline Endoscopic resection type, $n$ (\%) & & & 0.324 \\
\hline En bloc & $17(77)$ & $121(67)$ & \\
\hline Piecemeal & $5(23)$ & $60(33)$ & \\
\hline Median number of resected segments (range) & $3(2-9)$ & $3(2-11)$ & \\
\hline Median NPO duration after endoscopic resection (range), $d$ & $2(1-10)$ & $2(1-20)$ & 0.131 \\
\hline Median length of hospital stay after endoscopic resection (range), $d$ & $9(4-58)$ & $8(3-53)$ & 0.154 \\
\hline
\end{tabular}

RT, radiotherapy; EMR-C, endoscopic mucosal resection with cap-equipped pan-endoscope; ESD, endoscopic subepithelial dissection; ELPS, endoscopic laryngopharyngeal surgery; SD, standard deviation; NPO, nil per os (nothing by mouth).

Table 4 Complications associated with endoscopic resection procedures $(n=163)$.

\begin{tabular}{|c|c|c|c|}
\hline & $\begin{array}{l}\text { Post-RT sal- } \\
\text { vage }(n=16)\end{array}$ & $\begin{array}{l}\text { Non-RT } \\
(n=147)\end{array}$ & $P$ value \\
\hline Major complications, n (\%) & $1(6)$ & $17(12)$ & 0.912 \\
\hline Aspiration pneumonia & 1 & 4 & \\
\hline Subcutaneous emphysema & 0 & 4 & \\
\hline Delayed bleeding & 0 & 3 & \\
\hline Facial edema & 0 & 1 & \\
\hline Fever & 0 & 1 & \\
\hline Laryngeal edema & 0 & 2 & \\
\hline Difficult hemostasis & 0 & 1 & \\
\hline Delirium & 0 & 1 & \\
\hline Temporary tracheostomy, n(\%) & $3(19)$ & $28(19)$ & 0.977 \\
\hline
\end{tabular}

$\mathrm{RT}$, radiotherapy.

$66 \mathrm{~Gy})$. In 3 patients, local recurrence had developed at the primary site after a complete response to prior RT. The other 13 patients had multiple metachronous cancers in the radiation field. The groups did not statistically differ with regard to the percentage of lesions of the esophageal mucosa that did not stain with Lugol's iodine, which is considered to indicate a very high risk of multiple SCC in the region from the head and neck to the esophagus [22].

The baseline characteristics of the lesions in the post-RT salvage group ( $\mathrm{n}=22$ ) and non-RT group $(\mathrm{n}=181)$ are compared in $\bullet$ Table 2 . The post-RT salvage group had a significantly larger percentage of lesions with protrusion ( 0 -I or 0 -Ila; $P=0.044$ ). In both groups, most lesions were located in the hypopharynx.

\section{Clinical outcome of endoscopic resection}

Clinical results of the endoscopic resection procedures are listed in 0 Table 3. Differences between the groups in regard to procedure time, en bloc resection rate, duration of nil per os (NPO) status, and hospital stay after endoscopic resection were not statistically significant.

Complications are summarized in Table4. All complicated cases were successfully treated with conservative therapy. All patients were ultimately discharged without any loss of swallowing or speaking function.

Pathologic results are shown in Table5. The pathologically nonmalignant lesions in the endoscopic resection specimens included hyperplasia (acanthosis) in the post-RT salvage group, and two cases of moderate dysplasia and one of parakeratosis in the non-RT group. In both groups, a diagnosis of the resected margin could not be made in some cases (lateral, $40 \%$; vertical, $10 \%$ ) because of piecemeal specimens or burn effect. Statistically, no significant differences were observed between the post-RT salvage and non-RT groups undergoing endoscopic resection.

\section{Follow-up}

The patients' clinical course after endoscopic resection is summarized in Table6. With a median follow-up period of 37 months (range, 2- 72 months), 13 patients in the post-RT salvage group ( $81 \%$; $95 \% \mathrm{CI}, 59.8$ - 100) had no recurrence, whereas 2 patients (13\%; 95\% CI, 0-30.8) developed local recurrence and 1 patient (6\%; $95 \% \mathrm{CI}, 0-19.6)$ developed lymph node metastasis. The patients who had local recurrence had both undergone piecemeal resection with negative vertical margins and were cured by another endoscopic resection. At present, 5 of the 16 patients in the post-RT salvage group have died, 2 because of progression of head and neck cancer, 1 because of prior esophageal SCC, and the remaining 2 of unknown causes. Although 2 patients died of head and neck cancer, these patients had a local recurrence at the prior primary site after RT for advanced head and neck cancer. The duration of follow-up was 3 years or more for 8 patients (50 $\%)$, and the 3-year overall survival rate, recurrence-free survival rate, and disease-specific survival rate after salvage endoscopic resection were $68.6 \%$ (95\% CI, 42.7 - 94.5), 58.8\% (95\% CI, 30.487.2 ) and $81.8 \%$ (95\% CI, $59.1-100)$, respectively ( $\bullet$ Figs. $2-4)$.

\section{Discussion \\ $\nabla$}

We found that salvage endoscopic resection for node-negative locoregional failure after definitive RT for prior PSCC is safe and effective, with curative potential, and preserves laryngeal function. Locally recurrent lesions or metachronous lesions within the RT field exhibited fibrotic changes in the subepithelial layer on pathologic examination. The subepithelial dissections and injections of saline solution into the subepithelial layer to lift the lesion were performed with an endoscopic resection procedure. Although the fibrotic changes might have been expected to increase the difficulty of subepithelial dissection or lesion lifting, no statistically significant differences were found between the post-RT salvage endoscopic resection group and the non-RT endoscopic resection group in regard to en bloc resection rates, pathologic findings, complications, duration of hospitalization, and duration of nil per os (NPO) status. Fibrotic changes in the subepithelial layer might have been behind the statistically higher rate of macroscopic protrusion in the post-RT salvage endo- 


\begin{tabular}{|c|c|c|c|}
\hline & Post-RT salvage $(n=22)$ & Non-RT $(n=181)$ & $P$ value \\
\hline Depth of invasion, $n(\%)$ & & & 0.235 \\
\hline EP & $17(77)$ & $123(68)$ & \\
\hline SEP & $4(18)$ & $55(30)$ & \\
\hline Nonmalignant & $1(5)$ & $3(2)$ & \\
\hline Lymphatic invasion, $\mathrm{n}(\%)$ & & & 0.621 \\
\hline Present & $0(0)$ & $2(1)$ & \\
\hline Absent & $22(100)$ & $179(99)$ & \\
\hline Venous invasion, $\mathrm{n}(\%)$ & & & 0.190 \\
\hline Present & $2(9)$ & $6(3)$ & \\
\hline Absent & $20(91)$ & $175(97)$ & \\
\hline Lateral margin of specimen, $\mathrm{n}(\%)$ & & 0.687 & \\
\hline Negative & $6(27)$ & $65(36)$ & \\
\hline Positive & $7(32)$ & $46(25)$ & \\
\hline Difficult evaluation & $9(41)$ & $70(39)$ & \\
\hline Vertical margin of specimen, $n$ (\%) & & & 0.105 \\
\hline Negative & $18(82)$ & $160(88)$ & \\
\hline Positive & $2(9)$ & $3(2)$ & \\
\hline Difficult evaluation & $2(9)$ & $18(10)$ & \\
\hline Pathologic Tstage, n (\%) & & & 0.705 \\
\hline $\mathrm{T} 1$ & $17(77)$ & $138(76)$ & \\
\hline $\mathrm{T} 2$ & $4(18)$ & $38(21)$ & \\
\hline T3 & $0(0)$ & $2(1)$ & \\
\hline T4 & $0(0)$ & $0(0)$ & \\
\hline
\end{tabular}

Table 5 Results of pathologic examination of endoscopic resection specimens $(n=203)$.

RT, radiotherapy; EP, epithelial; SEP, subepithelial.

\begin{tabular}{|c|c|c|c|c|}
\hline & & Post-RT salvage $(n=16)$ & Non-RT $(n=147)$ & $P$ value \\
\hline \multicolumn{2}{|c|}{ Local failure, n (\%) } & $2(13)$ & $10(7)$ & 0.409 \\
\hline \multirow[t]{3}{*}{ Treatment } & Repeat endoscopic resection & 2 & 8 & \\
\hline & Partial resection & 0 & 1 & \\
\hline & No treatment & 0 & 1 & \\
\hline \multicolumn{2}{|c|}{ Neck lymph node metastasis } & $1(6)$ & $2(1)$ & 0.168 \\
\hline \multirow[t]{3}{*}{ Treatment } & Neck lymph node dissection & 1 & 0 & \\
\hline & Chemoradiotherapy & 0 & 1 & \\
\hline & No treatment & 0 & 1 & \\
\hline \multicolumn{5}{|c|}{ Cause of death, $n$} \\
\hline \multicolumn{2}{|c|}{ Esophageal squamous cell carcinoma } & 1 & 8 & \\
\hline \multicolumn{2}{|c|}{ Head and neck carcinoma } & 2 & 5 & 0.796 \\
\hline \multicolumn{2}{|c|}{ Other } & 0 & $9^{1}$ & \\
\hline \multicolumn{2}{|l|}{ Unknown } & 2 & 4 & \\
\hline
\end{tabular}

Table 6 Clinical course after endoscopic resection $(n=163)$.

RT, radiotherapy.

${ }^{1}$ Congestive heart failure $(n=2)$, lung cancer $(n=2)$, cerebral infarction $(n=1)$, cholangiocarcinoma $(n=1)$, colon cancer $(n=1)$, gastric cancer $(n=1)$, pancreatic cancer $(n=1)$.

scopic resection group compared with the non-RT group. Differences between the two groups in regard to depth of invasion, vessel invasion, $\mathrm{T}$ stage, and lymph node recurrence rate were not statistically significant. Furthermore, when all patients underwent NBI endoscopy at 3 months after endoscopic resection, the artificial ulcers were fully healed in both groups.

In the post-RT patients, laryngeal edema requiring tracheostomy was expected to occur more frequently than in the non-RT group. However, the incidences in the two groups were similar. This might be due to the fact that fewer lesions were located in the piriform sinus in the post-RT group. The lesions of all patients in the post-RT group who underwent tracheostomy were located in the piriform sinus. One case of aspiration pneumonia developed after salvage endoscopic resection, and this patient required a temporary tracheostomy. The other two patients received prophylactic tracheostomy for expected laryngeal edema.

Unfortunately, most patients with recurrence after definitive radiotherapy for PSCC require total laryngectomy [23,24]. Although this procedure has a high probability of controlling the tumor, it disrupts speech, and only $20 \%$ to $25 \%$ of patients are rehabilitated long term with a tracheoesophageal prosthesis [25]. Some radiation failures can be salvaged with conservative surgery, but partial laryngectomy is rarely performed because of anticipated postoperative problems, such as laryngeal stenosis, aspiration, delayed decannulation, and fistula formation [26,27]. The role of prophylactic neck dissection for patients undergoing surgical salvage is controversial. Some retrospective series of patients who underwent surgical salvage and simultaneous neck dissection observed a low risk of occult nodal metastases $[28,29]$. Transoral local treatment has the potential to be a salvage treatment for locoregional failure after radiation. Transoral laser microsurgery (TLM) provides a local alternative to open salvage surgery for selected patients with recurrent laryngeal and oropharyngeal cancer. One series of patients treated with TLM after previous RT or chemoradiotherapy (CRT) reported a 3-year overall survival rate of $52 \%$ [30]. Our study revealed a 3-year overall survival rate of $68.6 \%$, with a low rate of complications (6\%) and a short duration of hospitalization (median, 9 days). The main ad- 


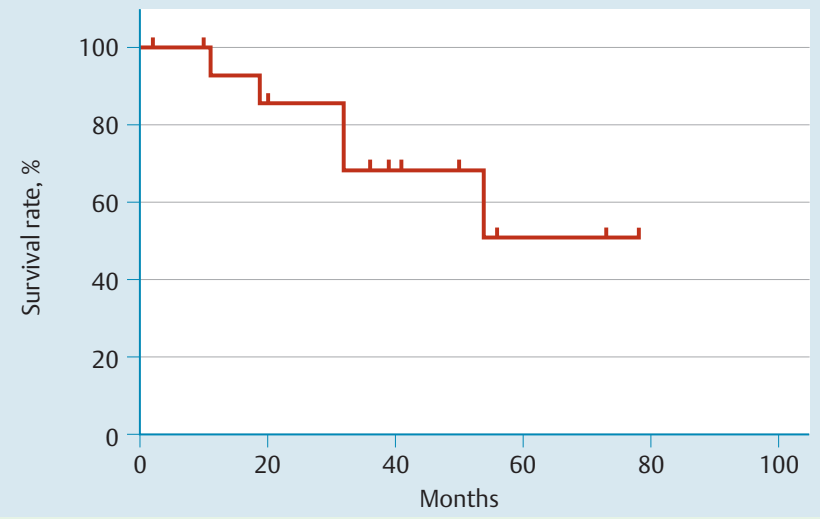

Fig. 2 Overall survival time after salvage endoscopic resection.

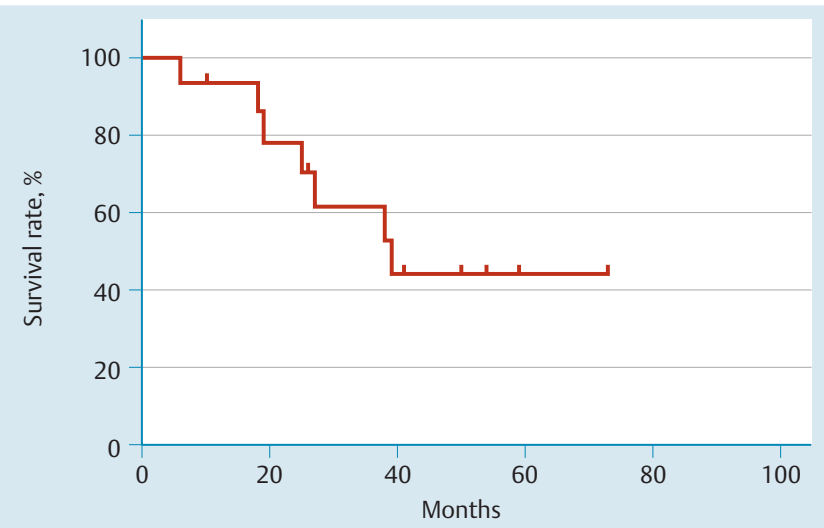

Fig.3 Recurrence-free survival time after salvage endoscopic resection.

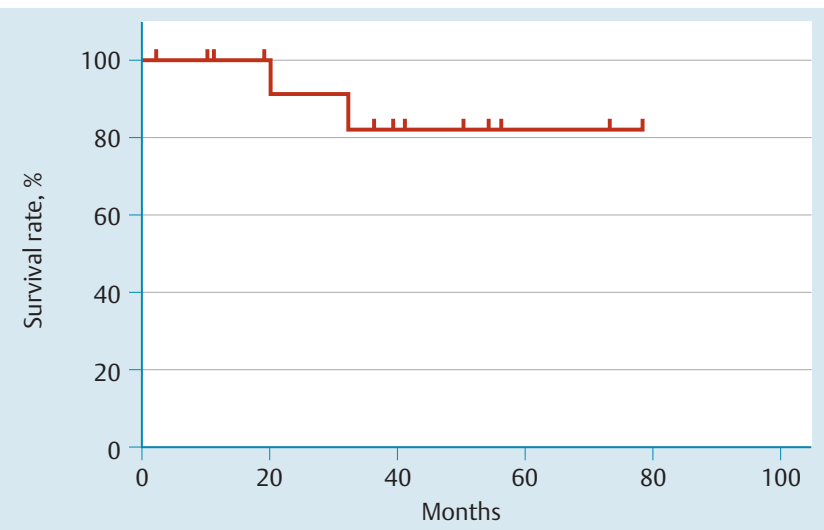

Fig.4 Disease-specific survival time after salvage endoscopic resection.

vantages of endoscopic resection is that it does not require opening of the thyroid cartilage, thus minimizing the risk of chondronecrosis. Salvage endoscopic resection is less invasive than salvage surgery for selected patients after failure of definitive RT. Endoscopic resection could be a curative treatment for superficial lesions, and early detection via a surveillance program with NBI endoscopy is therefore critically important, even for patients who have a history of radiation to the head and neck region. Salvage endoscopic resection is historically compared with other treatments in $\bullet$ Table 7.

Several limitations of this study should be discussed. First, our institution excluded lesions larger than $4 \mathrm{~cm}$ (T3) from endoscopic resection, as well as those suspected of being deeply invasive to the subepithelial layer. In addition, all patients evaluated in this study were clinically NOMO before endoscopic resection. The le-
Table 7 Historical comparison of salvage endoscopic resection and other treatments.

\begin{tabular}{|c|c|c|c|}
\hline & $\begin{array}{l}\text { Post-RT salvage } \\
\text { endoscopic re- } \\
\text { section }(n=16)\end{array}$ & $\begin{array}{l}\text { Post-RT sal- } \\
\text { vage TLM (n } \\
=62)[30]\end{array}$ & $\begin{array}{l}\text { Post-RT sal- } \\
\text { vage surgery } \\
(n=30)[29]\end{array}$ \\
\hline Median age, y & 64 & $65-67$ & 57 \\
\hline \multicolumn{4}{|l|}{$\begin{array}{l}\text { Prior lesion TNM } \\
\text { stage before RT, \% }\end{array}$} \\
\hline 1 & 6 & 20 & 0 \\
\hline II & 19 & 38 & 23 \\
\hline III & 6 & 30 & 27 \\
\hline IV & 25 & 6 & 50 \\
\hline Invalid ${ }^{1}$ & 44 & 6 & 0 \\
\hline TNM stage I-II, \% & 95 & 62 & $\mathrm{NE}$ \\
\hline \multicolumn{4}{|l|}{ Patients with } \\
\hline $\begin{array}{l}\text { 3-year overall } \\
\text { survival, \% }\end{array}$ & 68.3 & 52 & 55 \\
\hline Complications, \% & 6 & 16 & 40 \\
\hline \multicolumn{4}{|l|}{ Failure patterns } \\
\hline Local, \% & 13 & NE & 37 \\
\hline Nodal, \% & 6 & $\mathrm{NE}$ & 10 \\
\hline
\end{tabular}

RT, radiotherapy; TLM, transoral laser microsurgery; TNM, tumor node metastasis; NE, not evaluated.

${ }^{1}$ Invalid because primary tumor and regional lymph nodes could not be assessed (TX and NX).

sions may therefore have been at a lower risk of metastasizing than the usual targets of salvage surgical resection. As previously mentioned, the salvage endoscopic resection results for the postRT groups showed no statistical differences when compared with those of the non-RT groups. However, 5 patients in the non-RT group ( $3 \%$ ) had a prior history of CRT for cervical esophageal cancer in which the hypopharyngeal area had been within the radiation field, which may have affected the technical results of endoscopic resection in the non-RT group. Although our study included survival data for a relatively large population of patients who were treated with salvage endoscopic resection and who had more than 3 years of follow-up, it was performed at a single institution. Thus, a conclusive answer to the curability potential of salvage endoscopic resection will require that prospective trials be conducted at multiple institutions with a larger number of subjects and a longer follow-up.

In conclusion, this study suggests that endoscopic resection is a curative salvage treatment option for patients with locoregional failure after definitive radiation therapy for PSCC if the failure lesion is superficial or local.

\section{Competing interests: None}

\section{Institutions}

${ }^{1}$ Department of Gastroenterology Endoscopy Division, National Cancer Center Hospital East, Kashiwa, Japan

2 Pathology Division, Research Center for Innovative Oncology, National Cancer Center, Kashiwa, Japan

${ }^{3}$ Division of Radiation Oncology, National Cancer Center Hospital East,

Kashiwa, Japan

${ }^{4}$ Department of Head and Neck Surgery, National Cancer Center Hospital East, Kashiwa, Japan 


\section{Acknowledgments}

$\nabla$

The authors would like to thank Mari Takahashi for technical support. This study was presented in part at the 20th United European Gastroenterology Week, Amsterdam, the Netherlands, October 20-24, 2012.

\section{References}

1 Amdur RJ, Mendenhall WM, Stringer SP et al. Organ preservation with radiotherapy for T1-T2 carcinoma of the pyriform sinus. Head Neck 2001; 23: 353-362

2 Mendenhall WM, Riggs CE, Amdur RJ et al. Altered fractionation and/or adjuvant chemotherapy in definitive irradiation of squamous cell carcinoma of the head and neck. Laryngoscope 2003; 113: 546-551

3 Nakamura K, Shioyama Y, Kawashima M et al. Multi-institutional analysis of early squamous cell carcinoma of the hypopharynx treated with radical radiotherapy. Int J Radiat Oncol Biol Phys 2006; 65: 1045 - 1050

4 Slaughter DP, Southwick HW, Smejkal W. Field cancerization in oral stratified squamous epithelium; clinical implications of multicentric origin. Cancer 1953; 6: 963-968

5 McGuirt WF. Panendoscopy as a screening examination for simultaneous primary tumors in head and neck cancer: a prospective sequential study and review of the literature. Laryngoscope 1982; 92: 569576

6 Muto M, Nakame M, Katada C. Squamous cell carcinoma in situ at oropharyngeal and hypopharyngeal mucosal sites. Cancer 2004; 101 : $1375-1381$

7 Watanabe A, Tsujie $H$, Taniguchi $M$ et al. Laryngoscopic detection of pharyngeal carcinoma in situ with narrowband imaging. Laryngoscope 2006; 116: 650-654

8 Watanabe A, Taniguchi $M$, Tsujie $H$ et al. The value of narrow band imaging endoscope for early head and neck cancers. Otolaryngol Head Neck Surg 2008; 138: 446-451

9 Zabrodsky $M$, Lukes $P$, Lukesova $E$ et al. The role of narrow band imaging in the detection of recurrent laryngeal and hypopharyngeal cancer after curative radiotherapy. Biomed Res Int 2014; 2014: 175398

10 Yano T, Muto M, Hattori S et al. Long-term results of salvage endoscopic mucosal resection in patients with local failure after definitive chemoradiotherapy for esophageal squamous cell carcinoma. Endoscopy 2008; 40: 717-721

11 Muto M, Satake H, Yano T et al. Long-term outcome of transoral organpreserving pharyngeal endoscopic resection for superficial pharyngeal cancer. Gastrointest Endosc 2011; 74: 477-484

12 Iizuka T, Kikuchi D, Hoteya $S$ et al. Endoscopic submucosal dissection for treatment of mesopharyngeal and hypopharyngeal carcinomas. Endoscopy 2009; 41: 113-117

13 Iizuka T, Kikuchi D, Hoteya S et al. Clinical advantage of endoscopic submucosal dissection over endoscopic mucosal resection for early mesopharyngeal and hypopharyngeal cancers. Endoscopy 2011; 43: 839843

14 Suzuki H, Saito Y, Oda I et al. Feasibility of endoscopic mucosal resection for superficial pharyngeal cancer: a minimally invasive treatment. Endoscopy 2010; 42: 1 -7
15 Okada $K$, Tsuchida $T$, Ishiyama A et al. Endoscopic mucosal resection and endoscopic submucosal dissection for en bloc resection of superficial pharyngeal carcinomas. Endoscopy 2012; 44: 556-564

16 Yoshida T, Shimizu Y, Ono $S$ et al. Successful salvage endoscopic mucosal resection for residual superficial hypopharyngeal carcinoma after chemoradiotherapy, with long-term survival. Endoscopy 2009; 41: 568-569; author reply 570-561

17 Barnes D, Eveson JW, Reichart P, et al. eds. Pathology and genetics, head and neck tumors. (World Health Organization classification of tumours. Vol 9.) 3rd. edn. Lyon, France: IARC Press;118-121

18 Tani M, Sakai P, Kondo H. Endoscopic mucosal resection of superficial cancer in the stomach using the cap technique. Endoscopy 2003; 35: $348-355$

19 Japan Society for Head and Neck Cancer. General rules for clinical studies on head and neck cancer. 5th. edn. Tokyo, Japan: Kanehara Publishing Group; 2012: $58-65$

20 Kikuchi D, Iizuka T, Yamada A et al. Utility of magnifying endoscopy with narrow band imaging in determining the invasion depth of superficial pharyngeal cancer. Head Neck 2014: DOI 10.1002/hed.23683 Epub 2014 Mar 12

21 Fujii S, Yamazaki M, Muto M et al. Microvascular irregularities are associated with composition of squamous epithelial lesions and correlate with subepithelial invasion of superficial-type pharyngeal squamous cell carcinoma. Histopathology 2010; 56: 510-522

22 Muto M, Hironaka S, Nakane M. Association of multiple Lugol-voiding lesions with synchronous and metachronous esophageal squamous cell carcinoma in patients with head and neck cancer. Gastrointest Endosc 2002; 56: 517-521

$23 \mathrm{Lam} \mathrm{KH}$, Wei WI, Wong J et al. Surgical salvage of radiation failures in cancer of the larynx. J Laryngol Otol 1983; 97: 351-356

24 Shamboul K, Doyle-Kelly W, Bailey D. Results of salvage surgery following radical radiotherapy for laryngeal carcinoma. J Laryngol Otol 1984; 98: $905-907$

25 Mendenhall WM, Morris CG, Stringer SP et al. Voice rehabilitation after total laryngectomy and postoperative radiation therapy. J Clin Oncol 2002; 20: 2500-2505

26 Rodriguez-Cuevas S, Labastida S, Gonzalez D et al. Partial laryngectomy as salvage surgery for radiation failures in T1-T2 laryngeal cancer. Head Neck 1998; 20: 630-633

27 Watters GW, Patel SG, Rhys-Evans PH. Partial laryngectomy for recurrent laryngeal carcinoma. Clinical otolaryngology and allied sciences 2000; 25: 146-152

28 Dagan R, Morris CG, Kirwan JM et al. Elective neck dissection during salvage surgery for locally recurrent head and neck squamous cell carcinoma after radiotherapy with elective nodal irradiation. Laryngoscope 2010; 120: 945-952

29 Temam S, Koka V, Mamelle G et al. Treatment of the N0 neck during salvage surgery after radiotherapy of head and neck squamous cell carcinoma. Head Neck 2005; 27: 653-658

30 Grant DG, Salassa JR, Hinni ML et al. Transoral laser microsurgery for recurrent laryngeal and pharyngeal cancer. Otolaryngol Head Neck Surg 2008; 138: 606-613 